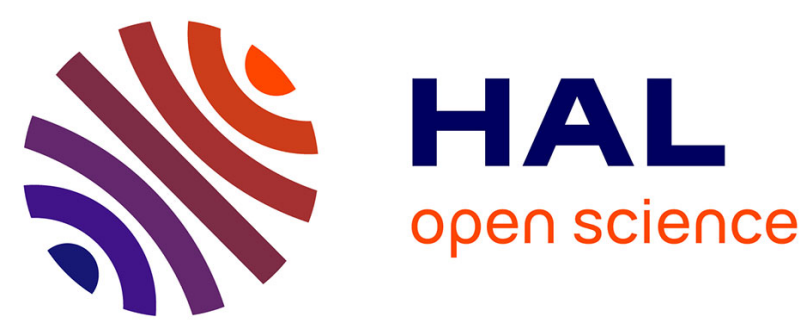

\title{
How terpene content affects fuel flammability of wildland-urban interface vegetation
}

\author{
Bastien Romero, Catherine Fernandez, Caroline Lecareux, Elena Ormeño, \\ Anne Ganteaume
}

\section{- To cite this version:}

Bastien Romero, Catherine Fernandez, Caroline Lecareux, Elena Ormeño, Anne Ganteaume. How terpene content affects fuel flammability of wildland-urban interface vegetation. International Journal of Wildland Fire, 2019, 28 (8), pp.614-627. 10.1071/WF18210 . hal-02281289

\section{HAL Id: hal-02281289 \\ https://hal-amu.archives-ouvertes.fr/hal-02281289}

Submitted on 16 May 2020

HAL is a multi-disciplinary open access archive for the deposit and dissemination of scientific research documents, whether they are published or not. The documents may come from teaching and research institutions in France or abroad, or from public or private research centers.
L'archive ouverte pluridisciplinaire HAL, est destinée au dépôt et à la diffusion de documents scientifiques de niveau recherche, publiés ou non, émanant des établissements d'enseignement et de recherche français ou étrangers, des laboratoires publics ou privés. 
$10 *$ Corresponding author : Anne Ganteaume

11 Address : Irstea Aix-en-Provence, Recover-EMR, 3275 route de Cézanne, 13182 Aix-en-Provence

12 cedex 5, France.

13 E-mail : anne.ganteaume@irstea.fr

14

15 Running head title: Role of terpenes on flammability 


\section{Abstract}

Among plant characteristics promoting flammability, terpenes have received far less attention, especially regarding the vegetation surrounding housing. Here, mono-, sesqui-, and diterpenes were screened in live and dead leaves of ornamental species found in Wildland-Urban Interfaces (WUI) of southeastern France. Terpene content and composition were compared among species and between fuel types. Their influence on flammability was assessed through several variables and compared to that of leaf thickness and moisture content. Six of the 17 species examined contained terpenes. Terpene diversity and content differed among species but not between fuel types. Mono-, sesqui-, and diterpenes (especially the highly concentrated compounds) were involved to varying degrees in both leaf and litter flammability. Their effects could be the opposite according to the flammability variable and the fuel type considered. Leaf sesquiterpene content and litter total terpene content had the strongest influence on maximum temperature; the former also mainly drove leaf flaming duration. The other flammability variables were more strongly associated with either moisture content or leaf thickness. Our findings underlined the idea that fire management in WUI must also acknowledge the potential for ornamental species containing terpenes, such as $P$. halepensis, in affecting fire behavior.

Key Words - Pinus halepensis; Fire prevention; Leaf traits; Fire-prone species; Ornamental vegetation; Volatile Organic Compounds

Short summary - We compared terpene content and composition in leaves of species found in Wildland-Urban Interfaces of southeastern France and evaluated their influence on flammability. Terpene content had the strongest influence on maximum temperature and flaming duration. Other 
flammability variables were more strongly associated with either moisture content or leaf thickness.

\section{Introduction}

Mediterranean regions are characterized by climatic conditions conducive to fire and these areas are often composed of highly flammable species. In some of these high fire risk areas, the human population has considerably increased wildfire frequency (Syphard et al. 2007; Ganteaume and Jappiot 2013), including wildland-urban interfaces (WUI) in southeastern France (Ganteaume and Long-Fournel 2015).

Plant species found in WUI (hereafter referred as "ornamental species" or "ornamental vegetation"), either native or exotic species, are important fuels during wildfires. Indeed, they can allow fire propagation from wildland vegetation to structures, possibly damaging or destroying buildings as highlighted during the destructive wildfires in 2016 in southeastern France (Ganteaume 2018a). Consequently, to better understand the role of the ornamental vegetation as a vector for the fire propagation (either due to massive firebrand showers or to the radiant heat emitted by the flame front), previous studies focused on the assessment of this vegetation's flammability (Ganteaume et al. 2013a, 2013b; Ganteaume 2018b). These works targeted both live leaf particles and dead surface fuels but did not consider the effect of volatile or non-volatile organic compounds on the flammability of these fuels.

Plant flammability has been widely studied and experimentally assessed under laboratory conditions as well as in situ during prescribed fires, for instance. Laboratory methods focus on deriving the metrics of flammability, such as the three major dimensions (i.e. ignitability, heat release and fire spread rate) recently highlighted in Pausas et al (2017), typically via the measurement of individual species fuels (leaf, litter bed, etc.). For a given fuel scale, these flammability dimensions are not necessarily correlated (Engber \& Varner 2012; Magalhães \& 
Schwilk 2012; Pausas \& Moreira 2012; Cornwell et al. 2015) and each of them has relevance across fuel scales (Pausas \& Moreira 2012). Previous works showed that these axes of flammability were primarily controlled by different plant traits (Scarff \& Westoby 2006; Engber at al. 2012; Schwilk \& Caprio 2011; Clarke et al. 2014), also called drivers of flammability. Some leaf traits continue to affect fuel bed flammability, scaling up from leaf to fuel bed (Varner et al. 2015). Among these characteristics, thickness was one of the main drivers of leaf ignitability (Murray et al. 2013; Grootemaat et al. 2015; Ganteaume 2018b) and can sometimes override the effects of other essential divers of leaf flammability (e.g., specific leaf area, surface area-to-volume ratio, or fuel moisture content as highlighted in several works, e.g., White and Zipperer 2010; Marino et al. 2011; Madrigal et al. 2013; Murray et al. 2013; Santoni et al. 2014; Grootemaat et al. 2015), as found in Ganteaume (2018b).

Along with fuel moisture content (FMC), terpenes are among the chemical compounds associated with flammability (Dimitrakopoulos 2001; Alessio et al. 2008a, 2008b). Indeed, some terpenes are volatile organic compounds naturally very flammable (Barboni et al. 2011) because of their high heating value, relatively low flash point, and low flammability limit (See, for instance, Sigma-Aldrich Data Sheets at https:/www.sigmaaldrich.com/united-kingdom/technicalservices/datasheets.html). Terpenes can be stored in the plant or directly emitted once synthesized, depending on their molecular weight. Their production and storage in the leaf require adapted structures such as resin ducts or trichomes (Martin et al. 2002), the location of these structures in the leaf depending on the species. These compounds are also involved in several ecological roles; for instance, coping with abiotic stresses (Paré and Tumlison 1999) such as water deficit (Peñuelas and Llusià 2003), or deterring herbivory as signal molecules in the communication between plants (Dicke et al. 2003) or between insects and plants (Pichersky and Gershenson 2002). Because of their chemical characteristics (such as low flash point), terpenes can also affect plant flammability. Even though, previous works linking terpene content and flammability are scarce as compared to 
those dealing with the impact of FMC or of other leaf traits. Most of these works investigated terpenes in live fuel, but only a few targeted both live and dead fuels such as Ormeño et al. (2009) and Della Rocca et al. (2017) for instance. Moreover, the previous works predominantly took into account either the total amount of terpenes without distinguishing subgroups (De Lillis et al. 2009) or focused on their most abundant fraction, the monoterpenes (White et al. 1994; Alessio et al. 2008a, 2008b), sometimes supplemented by the sesquiterpenes (Owens et al. 1998; Ormeño et al. 2009; Pausas et al. 2016; Della Rocca et al. 2017). Often, results as to these relationships were not conclusive or were contradictory (De Lillis et al. 2009; Alessio et al. 2008b). For instance, monoterpenes were found to enhance flammability in White et al. (1994) as well as in Owens et al. (1998) while sesquiterpenes positively affected flammability in Pausas et al. (2016) and in Della Rocca et al. (2017). These differences could sometimes be due to different species or terpene subgroups studied but not in every case (e.g., Alessio et al. 2008b and Della Rocca et al. 2017). Furthermore, excluding the works of Ormeño et al. (2009) or Della Rocca et al. (2017), flammability was mostly assessed through only one variable (such as time-to-ignition in Pausas et al. 2016), therefore lacking results on other flammability components. The positive impact of terpenes on plant flammability could be an issue in Mediterranean areas where summer drought induces a water stress that forces some species to increase their terpene production, and possibly their storage amount (Llusià and Peñuelas 1998; Ormeño et al. 2007; Genard-Zielinski et al. 2014) if they are able to store compounds, thereby making them potentially more flammable. Moreover, as large amounts of these compounds can be emitted in response to high temperatures (Centritto et al. 2011), episodes of massive terpene emission can result from wildfire events.

As far as we know, except for Pinus halepensis and Cupressus sempervirens, no previous studies have described in depth the live leaf and litter terpene content of ornamental species, especially neglecting to take into account different terpene subgroups (e.g., the volatile monoterpenes and sesquiterpenes, as well as the non-volatile diterpenes) and their influence on 
different flammability components. Filling these gaps would provide a better understanding of the live leaf and litter flammability processes regarding these chemical compounds. This is particularly important as terpene content might increase in response to the predicted warmer climatic conditions (Kleist et al. 2012), particularly as WUI species could be responsible for severe damage to buildings during a fire.

To tackle these goals, we i) screened for terpenes in the live and dead leaves of a wide range of common WUI species, characterizing the composition and concentration of terpenes, ii) determined if they differed between both fuel types within and among species, iii) examined the role of total terpene content and their constituent subgroups (e.g., monoterpenes, sesquiterpenes, diterpenes) on the flammability of these fuels, testing the hypothesis that terpenes would increase species' flammability, and iv) determined the relative importance of physical and chemical factors on flammability. Ultimately, focusing on a test species, we checked if these metrics varied between two different stages of plant maturity. This work, besides providing a better knowledge on the impact of terpenes on plant flammability, will also allow the identification of WUI species that could be deleterious during a fire regarding their specific terpene content.

\section{Material and Methods}

\section{Study Species and Sampling}

The species studied in the current work are common in the French Mediterranean WUI. They can be involved in the fire propagation from the wildland vegetation to the nearby buildings, especially regarding species used in ornamental hedges that provide strong horizontal fuel continuity. In total, seventeen of the most common ornamental species were studied (Suppl. Mat. 1) which, except for $P$. halepensis and Cotinus coggygria, have already been taken into account in the work of Ganteaume (2018b) in which these species' flammability was characterized. However, for most species, 
screening for terpenes in live and dead fuels had never been attempted. These ornamental species are composed of both native (e.g., Viburnum tinus, P. halepensis, or Cotinus coggygria) and exotic species (such as Thuja occidentalis). During a fire, some of them (e.g., P. halepensis, Cupressus sempervirens) can also cause damage and ignite buildings, as often witnessed by firefighters.

In order to highlight a possible variation in flammability according to plant maturity (that could be possibly linked to a variation in terpene content), one of the species studied, Cupressocyparis leylandii, was sampled in hedges differing in maturity (a young stage and an older stage corresponding to a mature plant). This species is commonly used in hedges at both stages.

For each species, two fuel types were targeted, live leaves (mentioned hereafter as "leaf" or "leaves") and dead leaves collected on the floor underneath the plants (mentioned hereafter as "litter"). The sampling was carried out in summer (July 2016) when the climate conditions were the most severe in southeastern France. Litter samples of C. coggygria could not be collected because of the rapid decomposition of the leaves preventing sufficient litter accumulation. Regarding dead fuel, we focused on dead individual leaves and not on the whole fuel bed (as done in previous works, e.g., Ganteaume et al. 2013a, 2018b). The physical arrangement of leaves in the litter bed (i.e. packing ratio) and the resulting air-to-fuel ratio has been shown to dominate the fuel bed flammability (Grootemaat et al. 2017), adding a supplementary parameter that could mask the effect of terpenes on flammability. For each species and each fuel type, a maximum of $25 \mathrm{~g}$ of mature live leaves and of intact dead leaves were collected on or underneath (for litter only) five different individuals, located at least $4 \mathrm{~m}$ apart. Per individual, $6 \mathrm{~g}$ were used for the burning experiments, $5 \mathrm{~g}$ for FMC measurements, and $1 \mathrm{~g}$ for the terpene analysis. Sampling was conducted at least $48 \mathrm{~h}$ following a precipitation event to avoid any impact of the recent rain on FMC. Litter samples were air-dried for $48 \mathrm{~h}$, time necessary for the stabilization of their weight; oven-drying was avoided as this process could involve the degradation of terpenes. As soon as their weight stabilized, the litter samples were burned. The live leaves sampled were placed in plastic bags and 
stored in a cool box for transportation to the laboratory, minimizing changes in water content; the samples were burned directly upon returning to the laboratory.

\section{Terpene content}

For the terpene analysis, leaf and litter samples were stored at $-80^{\circ} \mathrm{C}$ in order to stop leaf metabolism. For both fuel types, terpene content was analyzed for each species using $500 \mathrm{mg}$ of fuel collected from five different individuals and ground for extraction purposes using liquid nitrogen and put into a $4 \mathrm{~mL}$ of extraction solution (cyclohexane and dodecane). This vial was agitated for $30 \mathrm{~min}$, filtered (PTFE $-0.22 \mu \mathrm{m}$ filter), and put into a $3 \mathrm{~mL}$-vial for analysis. Dodecane was used as an internal standard and was not naturally present in the samples.

This analysis was conducted using gas chromatography (GC-MS System 7890B - Agilent Technologies $\left.{ }^{\circledR}\right)$. One microlitre was injected into a $30 \mathrm{~m}$ x $0.25 \mathrm{~mm}$ x $0.25 \mu \mathrm{m}$ thickness capillary column (HP-5MS - Agilent J\&W GC Columns), at a constant flow $\left(1 \mathrm{~mL} \mathrm{~min}^{-1}\right)$ and in the splitless mode. The injection temperature was maintained at $250^{\circ} \mathrm{C}$ with Helium (99.99\%) as the carrier gas. The initial temperature was $40^{\circ} \mathrm{C}$ and increased at $3^{\circ} \mathrm{C} \mathrm{min}^{-1}$ up to $300^{\circ} \mathrm{C}$ during analysis. A 5 minsolvent delay was respected and the total run time was 90 min.

The identification of terpenes was made using the molecule retention time (RT) as well as their mass spectrum which was compared to libraries in Adams (2007) and NIST (2011). To complete this identification, retention indexes (RI) were calculated for each molecule identified and compared to the libraries. We established these experimental RI from alkanes injected at each session:

$$
\mathrm{RI}_{(\mathrm{mol})}=100 \times X(\alpha)+\frac{R T(m o l)-R T(\alpha)}{R T(\beta)-R T(\alpha)} \times 100
$$

where $\alpha=$ alkane before the molecule, $\beta=$ alkane after the molecule, $X=$ Carbon number, and RT $=$ retention time.

To calculate the terpene content, several dilutions of many authentic reference compounds (Aldrich, Darmstadt, Germany and Firmenich, Geneva, Switzerland) were carried out in order to 
establish the response factor of the terpene subgroup as compared to the internal standard (dodecane). Then, the integrated area of each peak was multiplied by the appropriate response factor and divided by the sample volume. The sample dry mass was previously calculated to obtain the mass of terpene compound per dry mass unit. In the current work, we focused on the content of mono-, sesqui-, and diterpenes as well as on the total terpene content.

\section{Flammability Experiments}

Flammability experiments were carried out only on species containing terpenes in order to highlight the link between flammability and terpene content. Fuel samples were burned using a 500W epiradiator composed of a $10 \mathrm{~cm}$ radiant disk. A pilot flame was placed $4 \mathrm{~cm}$ above the epiradiator surface; this flame did not take part in the sample combustion but allowed a better ignition of the gases emitted by the plant before combustion (Hernando-Lara 2000). A thermocouple (chromelalumel, $\mathrm{k}$ type, $30 \mu \mathrm{m}$ diameter) was positioned $1 \mathrm{~cm}$ above the disk center to measure the temperature emitted by the radiant disk at a precise point $\left(300 \pm 30^{\circ} \mathrm{C}\right.$ that will trigger the leaf burning), then the temperature emitted by the flame when the sample burned. This thermocouple was linked to a data logger (ALEMO 2590 Ahlborn, Ahlborn Mess- und Regelungstechnik GmbH Holzkirchen, Germany) to record the variation of temperature (one record per second) during the burning. The burning device was turned on thirty minutes before the first burning test to be sure the epiradiator temperature was stabilized.

For each species, 30 one g-samples were burned; larger fuel masses increased the possibility that other fuel properties, such as fuel height, would cause differences in flammability (Ormeño et al. 2009). Thus, samples had to be as well distributed as possible on the radiant disk. As soon as the fuel was in contact with the epiradiator surface, time and temperature recordings were started. Five flammability variables were measured: i) time-to-ignition (TTI, s), defined as the time necessary for the fuel to ignite once laid on the radiant disk; ii) ignition temperature $\left(\mathrm{T}_{\mathrm{TTI}},{ }^{\circ} \mathrm{C}\right)$, defined as the 
temperature recorded when the flame appeared; iii) ignition frequency (IF, \%), calculated as the ratio between successful ignitions and the total number of samples ( $\mathrm{n}=30)$; iv) flaming duration (FD, s), time elapsed between the flame occurrence and its extinction; and v) maximum temperature emitted during burning $\left(\mathrm{T}_{\mathrm{MAX}},{ }^{\circ} \mathrm{C}\right)$. Live leaves were burned first to prevent chemical compound degradation and moisture content variation before the burning.

Just before the burning experiments, subsamples of litter and leaves of each individual were ovendried for $48 \mathrm{~h}$ at $60^{\circ} \mathrm{C}$ in order to measure their moisture content at the time of burning. FMC was calculated according to the following equation:

$\mathrm{FMC}=\frac{M f(g)-M d(g)}{M d(g)} \times 100$

where Mf represents the fresh fuel mass and Md represents the dry fuel mass.

Among the physical characteristics correlated with the leaf flammability of these species, leaf thickness was one of the most significant parameters because of the importance of this particle geometry in determining leaf combustion (Ganteaume 2018b). This parameter was chosen, along with FMC (also known to greatly influence flammability; Ganteaume et al. 2009) to be compared to terpene content as drivers of flammability. Immediately before burning, leaf thickness (Thi, $\mathrm{cm})$ was measured at the middle of the leaf (excluding the midrib), using a $10^{-4} \mathrm{~m}$ accuracy micrometer. A preliminary test showed that thickness did not significantly vary between live and dead leaves $(t=0.577413 ; p=0.565)$, so only live leaf thickness was used in the analyses.

\section{Data Analysis}

The statistical analyses were performed on each fuel dataset taking into account the content of the three terpene subgroups as well as the total terpene content (combining the three subgroups), FMC, and thickness as explanatory factors. The different flammability variables (using a single mean value per individuals of each species) were used as dependent variables. 
To compare species and stage of maturity on terpene content and flammability, we used oneway ANOVA. Regarding the stage of maturity, the Kruskal-Wallis test was performed instead of the Fisher test because of the lower amount of data. Comparisons between both litter and leaf

flammability and terpene content were performed using t-test. The normality of residual distribution was checked by the Kolmogorov-Smirnov test and data were log-transformed if needed. The post-hoc LSD test was used to check for significant differences between the different means $(\mathrm{p} \leq 0.05)$.

We used simple linear regression analyses to highlight (i) if flammability was more sensitive to the total terpene content or to terpene subgroups, and (ii) the significant correlations existing between flammability variables and fuel characteristics. When FMC and/or thickness explained a significant proportion of the variability of a given flammability variable, we used the residuals of the regression as a moisture/thickness-corrected measure of this variable. This corrected variable was then regressed against the terpene content in order to highlight the effect of terpenes without the bias of the above-mentioned factors (see Pausas et al. 2016). Partial least squares (PLS) regression analysis was performed to determine the relative importance of the physical and chemical fuel characteristics on each flammability variable. The significance of components for the models was determined by uncertainty tests carried out within a full cross-validation. Then, a bootstrap procedure (boot size $=1000$ ) was performed on the set of variables that presented the highest regression coefficients to rebuild the model, followed by a backwards elimination process until all explanatory variables were significant with p-values $\leq 0.05$. In order to take into account the flammability variables and fuel characteristics in a same analysis and to pinpoint the driving species of the relationships possibly highlighted, co-inertia analysis (Dolédec and Chessel 1994) was performed on both fuel datasets. The complete matrix of data was transferred to the statistical program under R 2.5.1 (R Development Core Team, 2005), then standardized and analysed using the ADE-4 package (Thioulouse et al. 1997). The statistical significance of each effect or 
combination of effects was tested using a Monte-Carlo permutation test with 1000 permutations using the R 'coin’ package.

All tests, except the bootstrap procedure (part of the PLS regression analyses) and co-inertia analyses, were performed using StatGraphics Centurion XVII - X64 software (StatPoint Technologies, Inc () .

\section{Results}

\section{Terpene Diversity and Content}

The screening for terpenes in the different species studied revealed that only six species among the seventeen studied contained terpenes, mostly conifers: $P$. halepensis, C. sempervirens, $T$. occidentalis, C. arizonica, C. leylandii (in both stages of maturity), and C. coggygria (Suppl. Mat. 2). We identified 54 different compounds in the leaves and litter of these species. The subgroup of sesquiterpenes was the most diverse (24 compounds, mostly in C. leylandii and C. arizonica), compared to that of diterpenes (19 compounds, mainly found in C. leylandii and in C. sempervirens) and monoterpenes (11 compounds, mostly in C. leylandii). C. leylandii presented the highest terpene diversity with more than 30 different compounds. C. coggygria's leaves contained only one compound, limonene (monoterpene).

Regarding the terpene content, monoterpenes presented the highest number of compounds with content higher than $0.1 \mathrm{mg} \mathrm{g}^{-1}$ dry matter (mentioned hereafter as "main compounds"), regardless of species and fuel type (Suppl. Mat. 3 and 4). However, the highest values were obtained for caryophyllene (sesquiterpene) in $P$. halepensis' leaves and litter $\left(0.905\right.$ and $0.866 \mathrm{mg} \mathrm{g}^{-1}$, respectively) and for nezukol (diterpene) in those of $T$. occidentalis $\left(0.870\right.$ and $0.940 \mathrm{mg} \mathrm{g}^{-1}$, respectively). C. sempervirens and $C$. arizonica presented the lowest terpene content $\left(<1.5 \mathrm{mg} \mathrm{g}^{-1}\right)$ despite the high terpene diversity screened in these species (12 main compounds for both fuel types). 
Regardless of the subgroup, terpene content differed among species (One way ANOVA: F=25.48 and $\mathrm{p}<0.0001$ for monoterpenes; $\mathrm{F}=16.61$ and $\mathrm{p}<0.0001$ for sesquiterpenes; $\mathrm{F}=25.22$ and $\mathrm{p}<0.0001$ for diterpenes), the highest content being observed in the mature leaves of $C$. leylandii (mainly due to their high number of different compounds) and the lowest in C. coggygria (presenting only one compound) (Fig. 1). Regarding live leaves (Fig. 1a), C. leylandii and P. halepensis stored the largest amounts of monoterpenes (> $2.00 \mathrm{mg} \mathrm{g}^{-1}$ and $1 \mathrm{mg} \mathrm{g}^{-1}$, respectively). It is worth noting that the amount of monoterpenes in C. coggygria (corresponding to limonene only) was in the same range $\left(\leq 0.5 \mathrm{mg} \mathrm{g}^{-1}\right)$ as in $C$. arizonica and $T$. occidentalis which presented several compounds belonging to this subgroup. P. halepensis presented the highest sesquiterpene content despite the small number of compounds contained in this species' leaves (around $1 \mathrm{mg} \mathrm{g}^{-1}$, mostly due to caryophyllene; Suppl. Mat. 3). C. leylandii and T. occidentalis presented the highest diterpene content (> $1 \mathrm{mg} \mathrm{g}^{-1}$ on average, mostly due to the high number of compounds in the former species and to nezukol in the latter). Regarding litter (Fig. 1 b), the three terpene subgroups differed significantly among species (One way ANOVA: $F=20.81$ and $\mathrm{p}<0.0001$ for monoterpenes; $F=13.63$ and $\mathrm{p}<0.0001$ for sesquiterpenes; $\mathrm{F}=33.89$ and $\mathrm{p}<0.0001$ for diterpenes). For litter, the different terpene subgroups were dominant in the same species as for leaves (Suppl. Mat. 4).

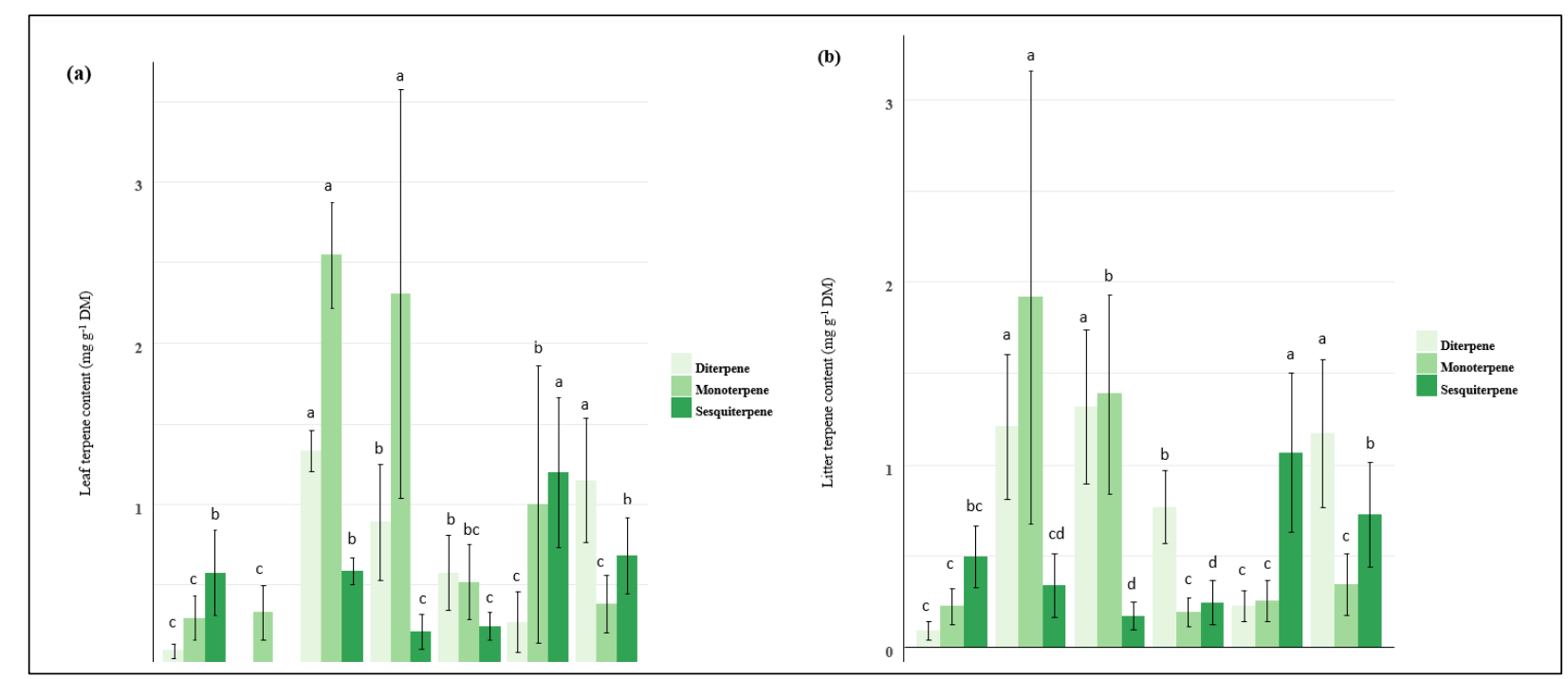


Figure 1: Comparison of the leaf (a) and litter (b) terpene content (means \pm SD) between species according to the three terpene subgroups. Means were calculated from the total terpene content of each individual. For each terpene subgroup, different letters indicate significant differences between species $(\mathrm{p}<0.05)$. No litter was sampled for Cotinus coggygria (Ca: Cupressus arizonica, $\mathrm{Cl}_{\mathrm{o}}$ and $\mathrm{Cl}_{\mathrm{y}}$ : mature and young Cupressocyparis leylandii, $\mathrm{Cc}$ : Cotinus coggygria, Cs: Cupressus sempervirens, Ph: Pinus halepensis, To: Thuya occidentalis). Lowercase letters indicate significant differences between species for each terpene subgroup.

Comparing leaves and litter, we found that the total terpene content did not vary between fuel types (all species pooled). The trend was the same when each terpene subgroup was considered individually. Accordingly, regarding terpene diversity, species were characterized mostly by the same compounds in both fuel types (Suppl. Mat. 3 and 4). Among monoterpenes, alpha-pinene was one of the most abundant compounds in most species, regardless of the fuel type. The results were mixed for the content of sesqui- and diterpenes, the most concentrated compound varying according to species (sesquiterpene caryophyllene in P. halepensis and diterpene nezukol in T. occidentalis, for instance), for both leaves and litter.

\section{Relationships Between Flammability and Fuel Characteristics}

Flammability was assessed for the six species containing terpenes (Table 1). For both fuel types, all the flammability variables but leaf $\mathrm{T}_{\mathrm{TTI}}$ (ranging between 319 and $\left.376^{\circ} \mathrm{C}\right)$ and litter IF $(100 \%$ for all species) significantly differed among species ( $<<0.0001)$. Litter flammability was significantly higher than that of leaves, except for $\mathrm{T}_{\text {TTI }}$ (TTI: $\mathrm{t}=12.33$, $\mathrm{p}<0.0001$; FD: $\mathrm{t}=-6.45, \mathrm{p}<0.0001$; $\mathrm{T}_{\text {MAX: }}$ $\mathrm{t}=-11.24, \mathrm{p}<0.0001) . P$. halepensis had the highest leaf flammability (higher $\mathrm{T}_{\mathrm{MAX}}$ and $\mathrm{IF}$, longer FD as well as shorter TTI and lower $\mathrm{T}_{\mathrm{TTI}}$ than the other species; Table 1); the results were mixed 
regarding litter flammability, several species (e.g., C. leylandii, P. halepensis, or C. sempervirens) presenting characteristics of high flammability (e.g., short TTI, high $\mathrm{T}_{\mathrm{MAX}}$ or IF, etc.).

Checking for a possible effect of other fuel characteristics (FMC and thickness) than terpene content, we found that FMC significantly impacted leaf TTI (positive effect) and IF (negative effect) while, for both fuel types, leaf thickness was significantly correlated with TTI (positive effect) and FD (negative effect and strongest relationship: $\mathrm{R}^{2}=0.75$ ) as well as with litter $\mathrm{T}_{\text {TTI }}$ (positive effect). These flammability variables were thus moisture and/or thickness-corrected when correlated with terpene content (Simple linear regression analyses; Table 2). Results revealed that terpene content could have a different impact on flammability from one fuel type to the other. Indeed, sesquiterpene content was negatively related to leaf TTI and to litter FD but positively to leaf $\mathrm{T}_{\mathrm{MAX}}$. In the same manner, diterpene content was negatively related to leaf FD (as was total terpene content) but positively to litter FD and TMAX (as was total terpene content regarding the latter variable). Leaf and litter $\mathrm{T}_{\mathrm{MAX}}$ were only impacted by terpene content (leaf sesquiterpenes and litter mono- and diterpenes, as well as litter total terpene content), highlighting the strong influence of terpenes on this variable. Leaf ignition frequency was not impacted by terpene content and there was no significant relationship between leaf $\mathrm{T}_{\text {TTI }}$ and any of the fuel characteristics. It is worth noting that, for both fuel types, most flammability variables were impacted by the content of one or several subgroups of terpenes rather than by the total terpene content.

Determining the relative importance of the physical and chemical fuel characteristics on flammability (PLS regression analyses, Table 3), we found that leaf thickness and FMC strongly impacted leaf TTI $\left(\mathrm{R}^{2}=0.73\right.$; positive effect) as well as FD (for the former), IF and TMAX (for the latter) but sesquiterpene content was the main driver of TMAX and FD (Table 3). Fuel characteristics were not significant drivers of leaf $\mathrm{T}_{\mathrm{TTI}}$, as previously highlighted in the simple linear regression analyses. When total terpene content was taken into account in the analyses instead of that of the 
different subgroups, the results were not significant for $\mathrm{T}_{\mathrm{MAX}}$ whereas the variability, explained in the analysis linking FD to thickness and terpene content, strongly increased (from $\mathrm{R}^{2}=0.26$ to 0.80), with a switch in the effect of the terpene content (negative for total terpene content instead of positive for sesquiterpene content). Regarding litter (Table 4), thickness was the only significant driver of litter TTI and $\mathrm{T}_{\text {TTI}}$; this fuel characteristic was also the most important driver of litter FD compared to the content of the three terpene subgroups. It is worth noting that, in this relationship, diterpene content negatively impacted litter FD contrary to the content of sesqui- and monoterpenes. Fuel characteristics did not impact litter $\mathrm{T}_{\mathrm{MAX}}$ (monoterpene content and diterpene content ceased to be significant after the bootstrap procedure) but when total terpene content was used in the analysis, this factor positively impacted flammability. When total terpene content was taken into account, FMC did not affect litter flammability except FD, overriding total terpene content, along with thickness (Table 4).

Most relationships between flammability variables and fuel characteristics previously highlighted were confirmed performing co-inertia analyses on both fuels' datasets (Fig. 2). Regarding leaf flammability (Fig. 2a), the first two axes explained $90.5 \%$ of the variance (61.2\% on axis 1). TTI and $\mathrm{T}_{\text {TTI }}$ (the latter however was not significant in the regression analyses) were opposed to FD on axis 1 (highest loading on this axis) and were mainly related to thickness (highest loading on this axis) and to mono- and diterpenes, at a lower extent (Suppl. Mat. 5). C. arizonica (presenting the thickest leaves) and C. coggygria (presenting the thinnest leaves) also displayed this opposition. $\mathrm{T}_{\mathrm{MAX}}$ best characterized axis 2 and was positively related to sesquiterpene content and FMC (Suppl. Mat. 5) on the positive side of this axis, confirming the results obtained in the regression analyses. This axis was best characterized by $P$. halepensis which presented the lowest FMC.

Regarding litter flammability (Fig. 2b), the two first axes explained $91 \%$ of the variance (50\% explained by axis 1). On the first axis, FD (and TTI as well as $\mathrm{T}_{\mathrm{TTI}}$, at a lower extent) was mainly 
negatively related to thickness (highest loadings on this axis; Suppl. Mat. 6); C. arizonica and T. occidentalis best characterizing this axis. On the second axis, $\mathrm{T}_{\mathrm{MAX}}$ was mainly positively related to mono- and diterpene content, $C$. leylandii (young stage) best characterizing these relationships. Litter IF was not taken into account in the analysis as this variable scored $100 \%$ for all species.

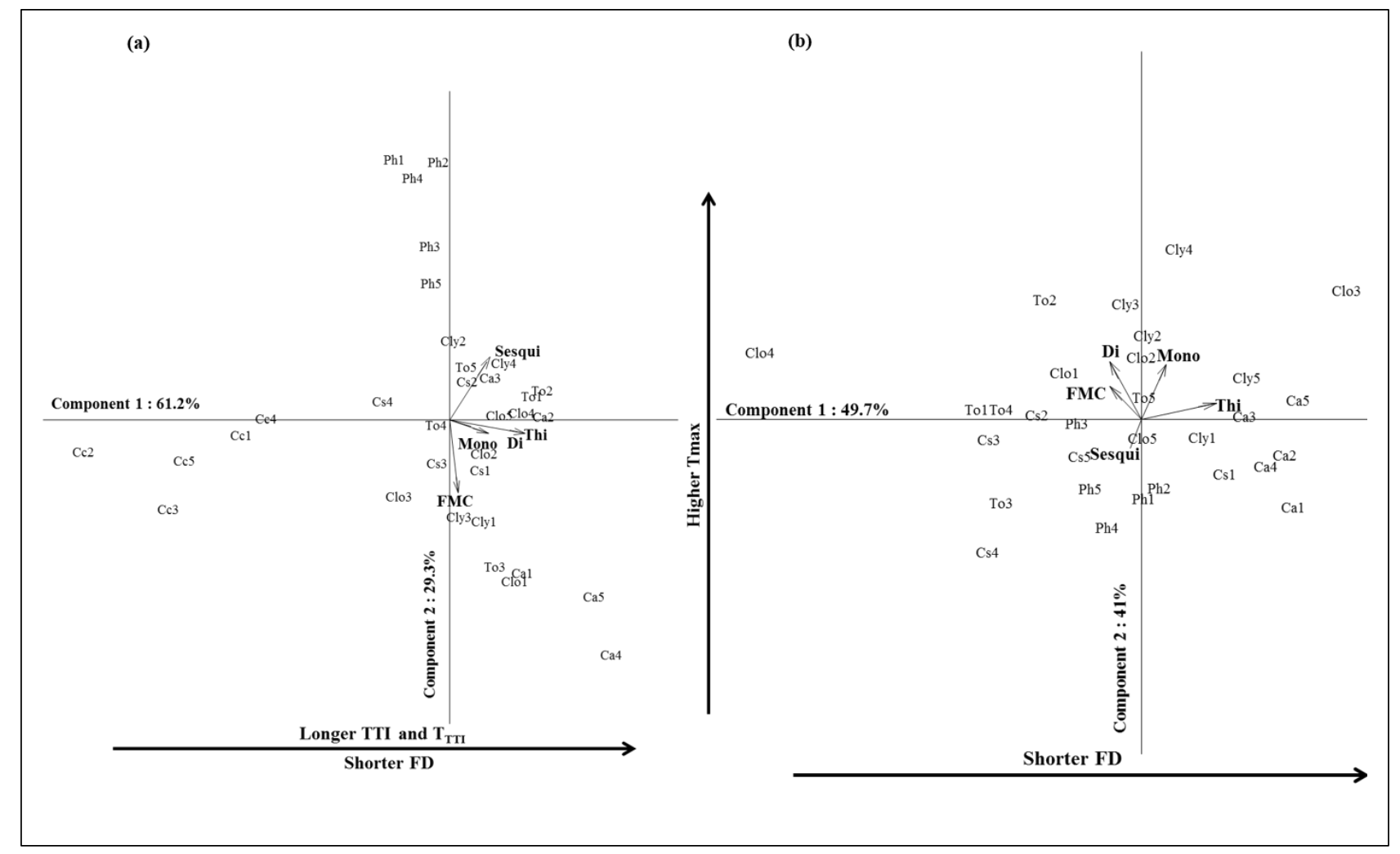

Figure 2: Biplots of co-inertia analysis illustrating relationships between leaf (a) and litter (b) flammability variables with fuel characteristics. In the litter dataset, IF was not taken into account, given it was $100 \%$ for all species and no litter was sampled for Cotinus coggygria (TMAX: maximum temperature, FD: flaming duration, IF: ignition frequency, TTI: time to ignition, $\mathrm{T}_{\mathrm{TTI}}$ : ignition temperature, Mono: monoterpene content, Sesqui: sesquiterpene content, Di: diterpene content, Thi: leaf thickness, FMC: fuel moisture content, $\mathrm{Ca}$ : Cupressus arizonica, $\mathrm{Cl}_{\mathrm{o}}$ and $\mathrm{Cl}_{\mathrm{y}}$ : mature and young Cupressocyparis leylandii, Cc: Cotinus coggygria, Cs: Cupressus sempervirens, Ph: Pinus halepensis, To: Thuya occidentalis). 


\section{Stage of Maturity}

C. leylandii presented the highest terpene diversity with 31 to 34 different compounds in the young and mature stages, respectively. These two maturity stages stored the largest amounts of monoterpenes (2.3 and $2.54 \mathrm{mg} \mathrm{g}^{-1}$, respectively) in their live leaves (Fig. 1a). Accordingly, this terpene subgroup was also the most abundant in litter of both mature and young plants, the content being higher in the mature stage (1.77 vs $\left.1.30 \mathrm{mg} \mathrm{g}^{-1}\right)$ (Fig. 1b).

Regarding leaf flammability, only FD differed significantly between the two stages of maturity $(\mathrm{KW}=4.08, \mathrm{p}=0.043)$, the mature plants presenting higher values (Tab. 2). Accordingly, FMC and the content of sesqui- and diterpenes were higher in this latter stage $(p \leq 0.05)$. When these parameters were used in the analysis, diterpene content and sesquiterpene content were the best drivers of leaf FD, this relationship explaining $65 \%$ of the variability. The stage of maturity did not impact litter flammability, regardless of the variable, even if FMC was lower in the mature plants contrary to sesquiterpene content (the only parameters significantly varying between litter of mature and young plants; $\mathrm{p} \leq 0.05)$.

\section{Discussion}

\section{Variation of terpenes according to species, fuel type, and stage of maturity}

The screening for terpenes in the live and dead leaves of the 17 species studied revealed that only six contained terpenes, all but $C$. coggygria being conifers. These species have storage structures for such organic compounds, e.g., resin ducts for $C$. leylandii, $T$. occidentalis, $C$. sempervirens, $C$. arizonica, and P. halepensis (Yani et al. 1993; Ormeño et al. 2008), and trichomes were found on the leaf surface of C. coggygria (Ormeño, pers. obs.). Terpene content and composition differed according to species but the main compounds (e.g., alpha-pinene, limonene, caryophyllene) found 
in the leaf and litter of the coniferous species we studied were consistent with compounds detected in previous studies (Gallis et al. 2007; Jitovetz et al. 2006; Chéraif et al. 2007). For C. coggygria, however, the monoterpene limonene was the only compound detected whereas Novakovic et al. (2007) also identified other monoterpenes (e.g., alpha-pinene and beta-pinene). Over all the terpenes screened, the sesquiterpene caryophyllene and diterpene nezukol were the most concentrated compounds (in P. halepensis and in T. occidentalis, respectively). The dominance of caryophyllene in $P$. halepensis' leaf has been highlighted in different areas of the Mediterranean Basin (Ioannou et al. 2014; Lahlou et al. 2003; Macchioni et al. 2003; Roussis et al. 1995; Tumen et al. 2010; Abi-Ayad et al. 2011).

Another important result of this work was that leaf and litter terpene content and diversity (total and by subgroup) did not differ within species nor between fuel types (54 compounds in both leaves and litter). Indeed, most terpenes are retained for long periods of time, e.g., in pine decomposed needles (Chomel et al. 2014); their polarity and chemical structure make them less degradable and/or leachable (White 1994; and the degradability decreases with the complexity of the molecule according to Kanerva et al. 2008). In both fuel types, the terpene content was higher in the mature stage of C. leylandii (regarding sesqui- and diterpenes), agreeing with the results of Peñuelas and Llusià (1997) on Rosmarinus officinalis and of Nowak et al. (2010).

\section{Impact of terpenes on flammability}

As expected, we found that litter was more flammable than live leaf (non-significant differences for ignition temperature) which was mostly due to lower FMC, as leaf thickness and terpene content did not differ from one fuel type to the other (regardless of the terpene subgroup). The total terpene content had only a limited effect on flammability (negative impact on leaf flaming duration but positive on litter maximum temperature) while this effect was more pronounced when the different subgroups were taken into account. Indeed, sesquiterpene content was one of the main 
driver of leaf flammability, increasing maximum temperature and flaming duration (to a lower extent, sesquiterpenes were also negatively correlated to time-to-ignition), agreeing with Della Rocca et al. (2017), but decreasing litter flaming duration, along with monoterpene content, according to Ormeño et al. (2009). Monoterpenes primarily affected litter flaming duration but did not have a predominant impact on leaf flammability. In contrast, Pausas et al. (2016) showed that most compounds significantly related to Rosmarinus officinalis' flammability (only based on leaf time-to-ignition) were monoterpenes while several works highlighted a negative impact of these compounds on leaf flammability (Owen et al. 1998; Alessio et al. 2008b; Della Rocca et al. 2017). Diterpene content, usually not studied in literature, impacted litter flaming duration only, but positively contrary to sesqui- and monoterpene content.

The impact of terpenes on flammability was mostly due to the influence of the most abundant compound of a subgroup (such as sesquiterpene caryophyllene in $P$. halepensis or diterpene nezukol in $T$. occidentalis). Indeed, leaves of P. halepensis were the most flammable (especially regarding both maximum temperature and flaming duration). Despite other species with high litter flammability features, this pine species had already been found as one of the most flammable and containing a high content of terpenes (Ormeño et al. 2009), especially caryophyllene, regardless of the fuel type. Another explanation of the highest flammability of pine's needle-leaves compared to the cypress' scale-leaves could be that the resin ducts, where the terpenes are stored, are located deeply in the pine needles (Bernard-Degan 1988) in contrast to the cypress' sub-epidermal resin glands (Castro and De Magistris 1999). This deeper location delays the vaporization of terpenes whose content will be thus higher when the plant burns. In the current work, we showed that the sesqui- and diterpenes stored in P. halepensis' live leaf and litter (high content in caryophyllene and cembrene, respectively) increased flammability, especially leaf maximum temperature for the former and litter flaming duration for the latter. These compounds could thus be considered as functional characteristics linked to fire in the same way as serotiny, for instance. Several other 
fire-prone species also presented high sesquiterpene content, such as some species of Cistus whose germination is triggered by fire; for instance, Cistus albidus and Cistus monspeliensis mainly synthesizing sesquiterpenes and, more precisely, caryophyllene for the latter (Llusià and Peñuelas 1998).

C. leylandii's mature stage presented longer leaf flaming duration (litter flammability did not differ between mature and young plants) and higher terpene content (especially cadina-1(6) 4 diene <cis> present only in the mature leaves) than the young plants, sesquiterpene content being the only significant driver of leaf flammability.

Our results also showed that terpene subgroups could have opposite effects (negative for sesquiand monoterpenes and positive for diterpenes regarding litter flaming duration, for instance). Moreover, a same subgroup (e.g., sesquiterpenes) could in turn enhance or mitigate a same flammability variable (for instance, flaming duration) from one fuel type to the other. This could be due to the higher FMC in live leaves suggesting interactions between sesquiterpenes and leaf water content. Our results highlight that greater terpene content does not necessarily mean greater flammability. Previous works already showed that different compounds belonging to the same terpene subgroup could have opposite effects on flammability (Owens et al. 1998; Della Rocca et al. 2017). We found that the terpene content did not affect some of the flammability variables (e.g., leaf ignition frequency, ignition temperature), agreeing with De Lillis et al. (2009). Sometimes this effect only appeared in the simple linear regressions (as for leaf time-to-ignition or litter maximum temperature), highlighting that other fuel characteristics could override the effect of terpenes on flammability.

\section{Relative importance of the different fuel characteristics on flammability}

Our results showed that terpenes did not affect ignitability, regardless of the fuel type, ignition frequency and time-to-ignition being primarily affected by thickness and/or FMC (but see Pausas 
et al. 2016 or Della Rocca et al. 2017). The effect of terpenes could be hampered by FMC, especially in live leaves (Alessio et al. 2008a; De Lillis et al. 2009) while this hypothesis was not confirmed in the work of Della Rocca et al. (2017). The role of water as terpenes' carrier, favouring or hampering their volatization during the pyrolysis should be investigated further. Indeed, terpenes could be dissolved in water, high FMC implying high terpene concentrations as suggested by Ciccioli et al. (2014).

In our experimental conditions (fuel collected in summer), FMC was a predominant factor only for leaf time-to-ignition, maximum temperature, and ignition frequency but was often overridden by leaf thickness or sesquiterpene content (except for ignition frequency). Blackmarr (1972) underlined the importance of exploring the effect of FMC and thickness at the same time because, when a fuel is thick, more energy is required for water evaporation before ignition becomes possible; that was clearly highlighted for $C$. arizonica's live leaf and litter (longest time-to-ignition as this species presented the thickest leaves and the highest FMC). Due to lower FMC in litter, thickness was the predominant driver of litter flammability (except for maximum temperature) whereas this factor impacted mostly leaf time-to-ignition, along with FMC. Monoterpene content was among the significant drivers of litter flaming duration, along with that of sesquiterpenes and diterpenes (the latter presenting an opposite effect) as well as with thickness; this result differed from that of Alessio et al. (2008b) who concluded that the effect of this terpene subgroup was overridden by leaf moisture content. It is worth noting that, for C. coggygria, the very low leaf thickness $(0.022 \mathrm{~mm})$ compared to others species could hinder the effects of the terpene content on flammability.

In the framework of climate change, more severe climate conditions (especially regarding drought) will involve a decrease in FMC which, according to our results, will be more easily overridden by other parameters such as terpene content. Under such conditions, the terpene content is expected to increase given its role in coping for water deficit, as shown in several works (increase 
in caryophyllene for Cistus monspeliensis as well as in alpha-pinene and delta-3-carene for $P$. halepensis according to Llusià and Peñuelas 1998, in monoterpenes for Picea abies and Pinus sylvestris according to Turtola et al. 2003, and for Salvia officinalis according to Nowak et al. 2010), thereby increasing plant flammability. This role would be especially marked in the more flammable fire-prone species of the Mediterranean region in summer (for P. halepensis or the other species studied that are native to this region) or in spring in Arizona (USA) for C. arizonica. The effect of terpene content on flammability will thus likely be more pronounced in the future.

\section{Conclusions}

Both terpene content and diversity varied according to species and to the stage of plant maturity but the terpene content did not significantly differ between fuel types. C. leylandii (especially the mature plants) had the most diverse spectrum and the highest total content (especially regarding monoterpenes) in both leaves and litter. Terpenes and especially leaf sesquiterpenes were involved to varying degrees in plant flammability, yet their effects could be the opposite according to the variable and the fuel type considered. Moreover, for each subgroup, the effect on flammability was mostly due to one compound, which was the most concentrated of the subgroup, showing that flammability was more sensitive to a particular subgroup and, further, to a particular compound than to the total terpene content. $P$. halepensis, presenting the highest leaf and litter sesquiterpene content (mostly due to caryophyllene), was the most flammable species (especially regarding live leaf); C. leylandii (mature plants) and T. occidentalis were the other most flammable litter. However, even if the terpene content took part in plant flammability, other factors must be considered, such as FMC and especially fuel thickness that could override the terpene content according to the flammability variable considered. Previous studies showed a seasonal variation of the leaf terpene content (along with FMC) in different species including P. halepensis (Owens 
et al. 1998; Staudt et al. 2000; Alessio et al. 2008a). In future works, it would be pertinent to highlight a possible seasonal variation of flammability according to the variation in moisture and terpene content throughout the year.

The current work underlined once more that, given the important role of ornamental vegetation in the fire propagation in WUI, the fire management in these areas must also acknowledge the potential for the species containing terpenes, such as $P$. halepensis, in affecting fire behaviour. Recommendations to home owners and forest managers should thus be provided accordingly. Indeed, our results confirmed that $P$. halepensis, already considered as a highly flammable species (Trabaud 2000; Dimitrakopoulos 2001), is a deleterious species in the case of a WUI fire and has often been responsible for significant damage to structures. Likewise, in T. occidentalis, the diterpene nezukol (which was also the terpene the most concentrated overall) played a significant part in the litter flammability of this species whose litter was also one of the most flammable. This highlighted once more the importance of cleaning the dead surface fuel from under the ornamental hedges in WUI.

Given that storing terpenes could be, for fire-prone species, an adaptive strategy to fire, it could be interesting to exhibit possible adaptations of species/populations to changes in fire regime (intraspecific variations in terpene content among populations undergoing different fire regimes or interspecific variations between two species that present different fire adaptive strategies such as the fire resistant Pinus sylvestris and the fire resilient P. halepensis).

\section{Acknowledgments}

We gratefully thank Amélie Saunier from the Institut Méditerranéen de Biodiversité et d'Ecologie (IMBE) for her help in the chemical analyses as well as Fabien Guerra, Ugo Furet, Christian Travaglini and Denis Morges (Irstea) for their help during the burning experiments. Authors also 
sincerely thank Aimee MacCormack for English revision. This research did not receive any specific funding.

\section{Conflict of interest statement}

The authors declare no conflicts of interest.

\section{References}

Abi-Ayad M, Abi-Ayad FZ, Lazzouni HA, Rebiahi SA, Ziani-Cherif C, Bessiere JM (2011) Chemical composition and antifungal activity of Aleppo pine essential oil. J Med Plants Res $\mathbf{5}$, 5433-5436.

Adams R (2007) Identification of essential oils by gas chromatography/mass spectrometry. Carol Stream: Allured Publishing Corporation, Carol Stream, IL.

Alessio G, Peñuelas J, Llusià J, Ogaya R, Estiarte M, De Lillis M (2008a) Influence of water and terpenes on flammability in some dominant Mediterranean species. International Journal of Wildland Fire 17, 274-286.

Alessio GA, Penuelas J, De Lillis M, Llusia J (2008b) Implications of foliar terpene content and hydration on leaf flammability of Quercus ilex and Pinus halepensis. Plant Biology 10, 123-8.

Anderson H (1970) Forest fuel ignitibility. Fire Technology 6, 312-319.

Barboni T, Cannac M, Leoni E, Chiaramonti N (2011) Emission of biogenic volatile organic compounds involved in eruptive fire: implications for the safety of firefighters. International Journal of Wildland Fire 20, 152-161. 
Bernard-Degan C (1988). Seasonal variations in energy sources and biosynthesis of terpenoids in maritime pine. In: "Mechanisms of Woody Plant Defenses Against Insects" (Mattson WJ, Levieux J, Bernard-Degan C eds). Springer, New York, USA, pp. 93-116.

Blackmarr W (1972) Moisture content influences ignitability of slash pine litter. Res. Note SE173. Asheville, NC: US Department of Agriculture, Forest Service, Southeastern Forest Experiment Station.7p.

Castro MA, De Magistris AA (1999). Ultrastructure of foliar secretory cavity in Cupressus arizonica var. glabra (Sudw.) Little (Cupressaceae). Biocell 23, 19-28.

Centritto M, Brilli F, Fodale R, Loreto F (2011) Different sensitivity of isoprene emission, respiration and photosynthesis to high growth temperature coupled with drought stress in black poplar (Populus nigra) saplings. Tree Physiology 31 (3), 275-286.

Chéraif I, Jannet HB, Hammami M, Khouja M, Mighri Z (2007) Chemical composition and antimicrobial activity of essential oils of Cupressus arizonica Greene. Biochemical Systematics and Ecology 35, 813-820.

Chomel M, Fernandez C, Bousquet-Mélou A, Gers C, Monnier Y, Santonja M, Gauquelin T, Gros R, Lecareux C, Baldy V (2014) Secondary metabolites of Pinus halepensis alter decomposer organisms and litter decomposition during afforestation of abandoned agricultural zones. Journal of Ecology 102, 411-424.

Chomel M, Guittonny-Larchevêque M, Fernandez C, Gallet C, DesRochers A, Paré D, Jackson BG, Baldy V (2016) Plant secondary metabolites: a key driver of litter decomposition and soil nutrient cycling. Journal of Ecology 104, 1527-1541.

Clarke PJ, Prior LD, French BJ, Vincent B, Knox KJE, Bowman DMJS (2014) Using a rainforestflame forest mosaic to test the hypothesis that leaf and litter fuel flammability is under natural selection. Oecologia 176, 1123-1133. 
Cornwell WK, Elvira A, van Kempen L, van Logtestijn RSP, Aptroot A, Cornelissen JHC (2015) Flammability across the gymnosperm phylogeny: the importance of litter particle size. New Phytologist 206, 672-681.

De Lillis M, Bianco PM, Loreto F (2009). The influence of leaf water content and terpenoids on flammability of some Mediterranean woody species. International Journal of Wildland Fire 18, 203-212.

Della Rocca G, Madrigal J, Marchi E, Michelozzi M, Moya B, Danti R (2017). Relevance of terpenoids on flammability of Mediterranean species: an experimental approach at a low radiant heat flux. iForest 10, 766-775. doi: 10.3832/ifor2327-010.

Dicke M, Agrawal AA, Bruin J (2003) Plants talk, but are they deaf? Trends in Plant Science 8, 403-405.

Dimitrakopoulos A (2001) A statistical classification of Mediterranean species based on their flammability components. International Journal of Wildland Fire 10, 113-118.

Dolédec S, Chessel D (1994) Co-inertia analysis: an alternative method for studying speciesenvironment relationships. Freshwater Biology 31, 277-294.

Engber EA, Varner JM (2012) Patterns of flammability of the California oaks: the role of leaf traits. Canadian Journal of Forest Research 42,1965-1975.

Gallis A, Doulis A, Papageorgiou A (2007) Variability of cortex terpene composition in Cupressus sempervirens L. provenances grown in Crete, Greece. Silvae Genetica 56, 294-299.

Ganteaume A (2018a) Role of the ornamental vegetation in the propagation of the Rognac fire (SE France, 2016). In "Fire Continuum Conference proceedings", May 21-24, 2018, Missoula, Montana (USA). In press.

Ganteaume A (2018b) Does plant flammability differ between leaf and litter bed scale? Role of fuel characteristics and consequences for flammability assessment. International Journal of Wildland Fire 27, 342-352.https://doi.org/10.1071/WF17001. 
Ganteaume A, Jappiot M (2013) What causes large fires in Southern France. Forest Ecology and Management 294, 76-85.

Ganteaume A, Lampin C, Guijarro M, Hernando C, Jappiot M, Fonturbel T, Perez-Gorostiaga P, Vega JA (2009) Spot fires: Fuel bed flammability and capability of firebrands to ignite fuel beds. International Journal of Wildland Fires 18, 951-969.

Ganteaume A, Jappiot M, Lampin C (2013a) Assessing the flammability of surface fuels beneath ornamental vegetation in wildland-urban interfaces in Provence (south-eastern France). International Journal of Wildland Fire 22, 333-342.

Ganteaume A, Jappiot M, Lampin C, Guijarro M, Hernando C (2013b) Flammability of some ornamental species in wildland-urban interfaces in southeastern France: laboratory assessment at particle level. Environmental Management 52, 467-480.

Ganteaume A, Long-Fournel M (2015) Driving factors of fire density can spatially vary at the local scale in south-eastern France. International Journal of Wildland Fire 24, 650-664.

Genard-Zielinski A-C, Ormeño E, Boissard C, Fernandez C (2014) Isoprene emissions from downy oak under water limitation during an entire growing season: what cost for growth? PloS One 9, e112418.

Grootemaat S, Wright IJ, Bodegom PM, Cornelissen JH, Cornwell WK (2015) Burn or rot: leaf traits explain why flammability and decomposability are decoupled across species. Functional Ecology 29, 1486-1497.

Grootemaat S, Wright IJ, van Bodegom PM, Cornelissen JH (2017) Scaling up flammability from individual leaves to fuel beds. Oikos 126, 1428-1438.

Hernando-Lara C (2000) Combustibles forestales: inflamabilidad. In 'La Defensa Contra Incendios Forestales, Fundamentos y Experiencias. McGraw-Hill: Madrid. 
Ioannou E, Koutsaviti A, Tzakou O, Roussis V (2014) The genus Pinus: a comparative study on the needle essential oil composition of 46 pine species. Phytochem Rev. 13: 741 - 768. DOI 10.1007/s11101-014-9338-4.

Jirovetz L, Buchbauer G, Stoilova I, Stoyanova A, Krastanov A, Schmidt E (2006) Chemical composition and antioxidant properties of clove leaf essential oil. Journal of Agricultural and Food Chemistry 54, 6303-6307.

Kanerva S, Kitunen V, Loponen J, Smolander A (2008) Phenolic compounds and terpenes in soil organic horizon layers under silver birch, Norway spruce and Scots pine. Biology and Fertility of Soils 44, 547-556.

Kleist E, Mentel TF, Andres S, Bohne A, Folkers A, Kiendler-Scharr A, Rudich Y, Springer M, Tillmann R, Wildt J (2012) Irreversible impacts of heat on the emissions of monoterpenes, sesquiterpenes, phenolic BVOC and green leaf volatiles from several tree species. Biogeosciences 9, 5111-5123.

Lahlou M (2003) Composition and molluscicidal properties of essential oils of five Moroccan Pinaceae. Pharm Biol 41, 207-210.

Lampin-Maillet C (2009) Caractérisation de la relation entre organisation spatiale d'un territoire et risque d'incendie: le cas des interfaces habitat-forêt du sud de la France. Aix-Marseille Université.

Llusià J, Peñuelas J (1998) Changes in terpene content and emission in potted Mediterranean woody plants under severe drought. Canadian Journal of Botany 76, 1366-1373.

Llusià J, Peñuelas J (2000) Seasonal patterns of terpene content and emission from seven Mediterranean woody species in field conditions. American Journal of Botany 87, 133-140.

Macchioni F, Cioni PL, Flamini G, Morelli I, Maccioni S, Ansaldi M (2003) Chemical composition of essential oils from needles, branches and cones of Pinus pinea, P. halepensis, P. pinaster and P. nigra from central Italy. Flavour Fragr J 18,139-143. 
Magalhães RMQ, Schwilk DW (2012) Leaf traits and litter flammability: evidence for nonadditive mixture effects in a temperate forest. Journal of Ecology 100, 1153-1163.

Martin D, Tholl D, Gershenzon J, Bohlmann J (2002) Methyl jasmonate induces traumatic resin ducts, terpenoid resin biosynthesis, and terpenoid accumulation in developing xylem of Norway spruce stems. Plant Physiology 129, 1003-1018.

Martin JT, Juniper BE (1970) The cuticles of plants. London: Edward Arnold.

Nazzaro F, Fratianni F, De Martino L, Coppola R, De Feo V (2013) Effect of essential oils on pathogenic bacteria. Pharmaceuticals 6, 1451-1474.

Nist X (2011) Ray photoelectron spectroscopy database, Version 3.5.: National Institute of Technology, Gaithersburg.

Novaković M, Vučković I, Janaćković P, Soković M, Filipović A, Tešević V, Milosavljević S (2007) Chemical composition, antibacterial and antifungal activity of the essential oils of Cotinus coggygria from Serbia. Journal of the Serbian Chemical Society 72, 1045-1051.

Ormeño E, Baldy V, Ballini C, Fernandez C (2008) Production and diversity of volatile terpenes from plants on calcareous and siliceous soils: effect of soil nutrients. Journal of Chemical Ecology 34, 1219-1229.

Ormeño E, Cespedes B, Sanchez IA, Velasco-García A, Moreno JM, Fernandez C, Baldy V (2009) The relationship between terpenes and flammability of leaf litter. Forest Ecology and Management 257, 471-482.

Ormeño E, Mevy J, Vila B, Bousquet-Melou A, Greff S, Bonin G, Fernandez C (2007) Water deficit stress induces different monoterpene and sesquiterpene emission changes in Mediterranean species. Relationship between terpene emissions and plant water potential. Chemosphere 67, 276-284.

Owens MK, Lin C-D, Taylor CA, Whisenant SG (1998) Seasonal patterns of plant flammability and monoterpenoid content in Juniperus ashei. Journal of Chemical Ecology 24, 2115-2129. 
Paré PW, Tumlinson JH (1999) Plant volatiles as a defense against insect herbivores. Plant Physiology 121, 325-332.

Pausas JG, Moreira B (2012) Flammability as a biological concept. New Phytologist 194, 610613.

Pausas JG, Keeley JE, Schwilk DW (2017) Flammability as an ecological and evolutionary driver. Journal of Ecology 105, 289-297.

Pausas J, Alessio G, Moreira B, Segarra-Moragues J (2016) Secondary compounds enhance flammability in a Mediterranean plant. Oecologia 180, 103-110.

Peñuelas J, Llusià J (1997) Effects of carbon dioxide, water supply, and seasonality on terpene content and emission by Rosmarinus officinalis. Journal of Chemical Ecology 23, 979-993.

Peñuelas J, Llusià J (2003) BVOCs: plant defense against climate warming? Trends in Plant Science 8, 105-109.

Perez-Harguindeguy N, Diaz S, Garnier E, Lavorel S, Poorter H, Jaureguiberry P, Bret-Harte M, Cornwell WK, Craine JM, Gurvich DE (2013) New handbook for standardised measurement of plant functional traits worldwide. Australian Journal of Botany 61, 167-234.

Pichersky E, Gershenzon J (2002) The formation and function of plant volatiles: perfumes for pollinator attraction and defense. Current Opinion in Plant Biology 5, 237-243.

Roussis V, Petrakis PV, Ortiz A, Mazomenos BE (1995) Volatiles constituents of needles of five Pinus species gown in Greece. Phytochemistry 39,357-361.

Scarff FR, Westoby M (2006) Leaf litter flammability in some semi-arid Australian woodlands. Functional Ecology 20, 745-752.

Schwilk DW, Caprio AC (2011) Scaling from leaf traits to fire behaviour: community composition predicts fire severity in a temperate forest. Journal of Ecology 99, 970-980. 
Staudt M, Bertin N, Frenzel B, Seufert G (2000) Seasonal variation in amount and composition of monoterpenes emitted by young Pinus pinea trees-implications for emission modeling. Journal of Atmospheric Chemistry 35, 77-99.

Syphard AD, Radeloff VC, Keeley JE, Hawbaker TJ, Clayton MK, Stewart SI, Hammer RB (2007) Human influence on California fire regimes. Ecological Applications 17, 1388-1402.

Thioulouse J, Chessel D, Dole S, Olivier J-M (1997) ADE-4: a multivariate analysis and graphical display software. Statistics and Computing 7, 75-83.

Trabaud L (2000) Post-fire regeneration of Pinus halepensis forests in the West Mediterranean. Ecology, Biogeography and Management of Pinus halepensis and P. brutia Forest Ecosystems in the Mediterranean Basin. Backhuys Publishers, Leiden, The Netherlands, 257-268.

Tumen I, Hafizoglu H, Kilic A, Do“nmez IE, Sivrikaya H, Reunanen M (2010) Yields and constituents of essential oil from cones of Pinaceae spp. natively grown in Turkey. Molecules 15, 5797-5806.

Turtola S, Manninen AM, Rikala R, Kainulainen P (2003) Drought stress alters the concentration of wood terpenoids in Scots pine and Norway spruce seedlings. J. Chem. Ecol. 29, 1981-1995.

Varner JM, Kane JM, Kreye JK, Engber E (2015) The flammability of forest and woodland litter: a synthesis. Current Forestry Reports 1, 91-99. doi: 10.1007/s40725-015-0012-x

White CS (1994) Monoterpenes: their effects on ecosystem nutrient cycling. Journal of Chemical Ecology 20, 1381-1406.

White RH, Zipperer WC (2010) Testing and classification of individual plants for fire behaviour: plant selection for the wildland-urban interface. International Journal of Wildland Fire 19, 213-227.

Yani A, Pauly G, Faye M, Salin F, Gleizes M (1993) The effect of a long-term water stress on the metabolism and emission of terpenes of the foliage of Cupressus sempervirens. Plant, Cell \& Environment 16, 975-981. 
Table 1. Flammability variables (means $\pm S D, n=30$ ) according to species and fuel types (TMAX: maximum temperature, TTI: time-to-ignition, $\mathrm{T}_{\mathrm{TTI}}$ : ignition temperature; FD: flaming duration, and IF: ignition frequency; Ca: Cupressus arizonica, $\mathrm{Cl}_{\mathrm{y}}$ and $\mathrm{Cl}_{\mathrm{o}}$ : young and mature Cupressocyparis leylandii, Cc: Cotinus coggygria, Cs: Cupressus sempervirens, Ph: Pinus halepensis, To: Thuja occidentalis. C. coggygria's litter was not collected).

792

793

\begin{tabular}{|c|c|c|c|c|c|}
\hline Species & $\mathbf{T}_{\text {MAX }}\left({ }^{\circ} \mathrm{C}\right)$ & TTI (s) & FD (s) & $\mathbf{T}_{\text {TTI }}\left({ }^{\circ} \mathrm{C}\right)$ & IF (\%) \\
\hline \multicolumn{6}{|c|}{ LEAF } \\
\hline $\mathbf{P h}$ & $545 \pm 39.2$ & $14 \pm 2.4$ & $13.9 \pm 3.1$ & $318.7 \pm 17$ & 100 \\
\hline Cs & $428.4 \pm 17.7$ & $26.3 \pm 5.1$ & $10.6 \pm 1.6$ & $334.4 \pm 26.6$ & 81 \\
\hline $\mathbf{C a}$ & $454.2 \pm 39.9$ & $41.3 \pm 10.2$ & $11.1 \pm 3.9$ & $375.9 \pm 32.7$ & 90 \\
\hline $\mathrm{Cl}_{\mathbf{y}}$ & $420 \pm 58.1$ & $27.1 \pm 6.6$ & $7.9 \pm 1.9$ & $354.8 \pm 23.5$ & 81 \\
\hline $\mathrm{Cl}_{\mathbf{O}}$ & $459.1 \pm 35.5$ & $29.4 \pm 3.9$ & $12.4 \pm 2.2$ & $363.6 \pm 45.7$ & 70 \\
\hline To & $466 \pm 34.1$ & $26.3 \pm 2.4$ & $9.6 \pm 2.4$ & $362.3 \pm 21.7$ & 87 \\
\hline Ce & $400.5 \pm 46.5$ & $16.9 \pm 6.6$ & $8.82 \pm 4.1$ & $323.7 \pm 29.2$ & 77 \\
\hline \multicolumn{6}{|c|}{ LITTER } \\
\hline $\mathbf{P h}$ & $589.4 \pm 34.9$ & $2.5 \pm 0.8$ & $14.6 \pm 3.6$ & $352.5 \pm 30.7$ & 100 \\
\hline Cs & $551.7 \pm 100.6$ & $3.3 \pm 0.7$ & $21 \pm 4.8$ & $335.1 \pm 31.6$ & 100 \\
\hline $\mathbf{C a}$ & $569.2 \pm 66.4$ & $3.5 \pm 0.8$ & $12.6 \pm 3.5$ & $382.3 \pm 54$ & 100 \\
\hline $\mathrm{Cl}_{\mathbf{y}}$ & $628.9 \pm 48.2$ & $3.2 \pm 0.9$ & $14.9 \pm 3.5$ & $371.8 \pm 35.8$ & 100 \\
\hline $\mathrm{Cl}_{\mathrm{o}}$ & $619.4 \pm 45.7$ & $3.2 \pm 1.4$ & $18.5 \pm 5.3$ & $352.5 \pm 63.9$ & 100 \\
\hline To & $612.6 \pm 56.4$ & $2.6 \pm 0.8$ & $19.6 \pm 5.5$ & $351.9 \pm 41.8$ & 100 \\
\hline Ce & - & - & - & - & \\
\hline
\end{tabular}


2 Table 2: Relationships obtained between leaf and litter flammability variables with fuel characteristics using simple linear regression analyses.

3 Litter IF was not taken into account as this variable scored $100 \%$ in all the species (in bold: significant relationships, in italic: analyses performed

4 on moisture and/or thickness-corrected flammability variable; R: correlation coefficient giving the sign of the relationship, $\mathrm{R}^{2}$ : adjusted coefficient

5 of determination, and p: p-value; $\mathrm{T}_{\mathrm{MAX}}$ : Maximum temperature, TTI: time-to-ignition, FD: flaming duration, $\mathrm{T}_{\mathrm{TTI}}$ : ignition temperature, IF: ignition

6 frequency).

\begin{tabular}{|c|c|c|c|c|c|c|}
\hline LEAF & FMC & Thickness & Monoterpenes & Sesquiterpenes & Diterpenes & Total Terpenes \\
\hline $\mathrm{T}_{\mathrm{MAX}}$ & NS & NS & NS & $\begin{array}{c}F=25.87 ; p<0.0001 \\
R=0.71 ; R^{2}=0.48\end{array}$ & NS & NS \\
\hline TTI & $\begin{array}{l}F=13.28 ; p=0.001 \\
R=0.55 ; R^{2}=0.28\end{array}$ & $\begin{array}{c}F=19.57 ; p=0.0001 \\
R=0.62 ; R^{2}=0.37\end{array}$ & NS & $\begin{array}{c}F=6.67 ; p=0.016 \\
R=-0.45 ; R^{2}=0.17\end{array}$ & NS & NS \\
\hline FD & NS & $\begin{array}{l}F=95.95 ; p<0.0001 \\
r R=-0.87 ; R^{2}=0.75\end{array}$ & NS & NS & $\begin{array}{c}F=9.68 ; p=0.005 \\
R=-0.52 ; R^{2}=0.24\end{array}$ & $\begin{array}{c}F=5.70 ; p=0.023 \\
R=-0.39 ; R^{2}=0.13\end{array}$ \\
\hline $\mathrm{T}_{\mathrm{TTI}}$ & NS & NS & NS & NS & NS & NS \\
\hline IF & $\begin{array}{c}F=8.97 ; p=0.020 \\
R=-0.40 ; R^{2}=0.13\end{array}$ & NS & NS & $N S$ & NS & NS \\
\hline
\end{tabular}




\begin{tabular}{|c|c|c|c|c|c|c|}
\hline LITTER & FMC & Thickness & Monoterpenes & Sesquiterpenes & Diterpenes & Total Terpenes \\
\hline $\mathrm{T}_{\text {MAX }}$ & NS & NS & $\begin{array}{l}F=6.44 ; p=0.017 \\
R=0.43 ; R^{2}=0.16\end{array}$ & NS & $\begin{array}{l}F=7.61 ; p=0.010 \\
R=0.46 ; R^{2}=0.19\end{array}$ & $\begin{array}{l}F=10.62 ; p=0.003 \\
R=0.52 ; R^{2}=0.25\end{array}$ \\
\hline TTI & NS & $\begin{array}{l}F=7.11 ; p=0.013 \\
R=0.45 ; R^{2}=0.17\end{array}$ & $N S$ & $N S$ & $N S$ & $N S$ \\
\hline FD & NS & $\begin{array}{c}F=6.36 ; p=0.018 \\
R=-0.43 ; R^{2}=0.16\end{array}$ & $N S$ & $\begin{array}{c}F=6.06 ; p=0.020 \\
R=-0.42 ; R^{2}=0.15\end{array}$ & $\begin{array}{l}F=4.75 ; p=0.038 \\
R=0.38 ; R^{2}=0.11\end{array}$ & $N S$ \\
\hline $\mathrm{T}_{\mathrm{TTI}}$ & NS & $\begin{array}{l}F=6.87 ; p=0.014 \\
R=0.44 ; R^{2}=0.17\end{array}$ & $N S$ & $N S$ & $N S$ & $N S$ \\
\hline
\end{tabular}


1 Table 3. Results of the partial least squares regression analyses (PLS) highlighting the significant fuel characteristics impacting leaf flammability 2 variables. A second PLS was run after the bootstrap procedure to obtain the correlation coefficients of the significant variables. Analyses were 3 separately run taking into account either the terpene content of the different subgroups or the total terpene content (in bold: significant fuel characteristics, $\mathrm{p}$ : $\mathrm{p}$ value, $\mathrm{R}^{2}$ : adjusted coefficient of determination, $\mathrm{R}$ : correlation coefficient; TTI: time-to-ignition, $\mathrm{T}_{\mathrm{MAX}}$ maximal temperature,

5 FD: flaming duration, IF : ignition frequency, $\mathrm{T}_{\mathrm{TTI}}$ : ignition temperature, FMC: fuel moisture content, Thi: leaf thickness, Mono: monoterpene

6 content, Sesqui: sesquiterpene content, Di: diterpene content, Terp_tot : total terpene content; bootstrap p-value: *** $: \mathrm{p}>0.01, * * * \mathrm{p}=0.01, *$ :

$7 \mathrm{p}=0.05$, boot size $=1000$ ).

\begin{tabular}{|c|c|c|c|c|c|c|c|c|}
\hline \multirow{2}{*}{$\begin{array}{l}\text { Flammability } \\
\text { variable }\end{array}$} & \multicolumn{2}{|c|}{ Analyses with content of terpene } & \multicolumn{2}{|c|}{ subgroups } & \multicolumn{4}{|c|}{ Analyses with total terpene content } \\
\hline & Results of PLS1 & After boostrap & P-value & Results of PLS2 & Results of PLS1 & After boostrap & P-value & Results of PLS2 \\
\hline \multirow[t]{6}{*}{ TTI } & $\mathrm{p}<0.0001, \mathrm{R}^{2}=0.82$ & & & $\mathrm{p}<0.0001, \mathrm{R}^{2}=0.73$ & $\mathrm{p}<0.0001, \mathrm{R}^{2}=0.74$ & & & $\mathrm{p}<0.0001, \mathrm{R}^{2}=0.73$ \\
\hline & Thi: $\mathbf{R = 0 . 4 5}$ & Thi & $* * *$ & Thi: $\mathbf{R = 0 . 6 5}$ & Thi: $\mathbf{R = 0 . 7 0}$ & Thi & $* * *$ & Thi: $\mathbf{R}=\mathbf{0 . 6 5}$ \\
\hline & FMC: $\mathbf{R}=\mathbf{0 . 6 7}$ & FMC & $* * *$ & FMC: $\mathbf{R}=\mathbf{0 . 5 8}$ & FMC: $\mathbf{R}=\mathbf{0 . 5 8}$ & FMC & $* * *$ & FMC: $\mathbf{R}=\mathbf{0 . 5 8}$ \\
\hline & Mono: $\mathrm{R}=-0.006$ & & & & Terp_tot: $R=-0.13$ & & & \\
\hline & Sesqui: $R=-0.16$ & & & & & & & \\
\hline & Di: $R=-0.05$ & & & & & & & \\
\hline \multirow[t]{2}{*}{ Tmax } & $\mathrm{p}=0.0002, \mathrm{R}^{2}=0.65$ & FMC & $* * *$ & $\mathrm{p}<0.0001, \mathrm{R}^{2}=0.60$ & NS & & & \\
\hline & Thi: $R=0.13$ & Sesqui & $* * *$ & FMC: $R=-0.32$ & & & & \\
\hline
\end{tabular}


FMC: $\mathbf{R}=\mathbf{- 0 . 4 3}$

Mono: $\mathbf{R}=\mathbf{- 0 . 2 4}$

Sesqui: $\mathbf{R}=\mathbf{0 . 8 3}$

Di: $\mathbf{R}=\mathbf{0 . 2 7}$

FD

$\mathrm{p}=0.003, \mathrm{R}^{2}=0.29 \quad$ Thi

Thi: $\mathbf{R}=-0.6$

FMC: $\mathrm{R}=-0.02$

Mono: $\mathrm{R}=-0.09$

Sesqui: $\mathbf{R}=\mathbf{0 . 3 4}$

Di: $R=-0.08$

IF

$\mathrm{p}=0.010, \mathrm{R}^{2}=0.23 \quad$ FMC

FMC: $\mathbf{R}=-\mathbf{0 . 3 1}$

Mono: $\mathrm{R}=-0.10$

Sesqui: $\mathrm{R}=-0.02$

Di: $R=-0.24$

\section{Sesqui: $\mathbf{R}=0.73$}

\section{Sesqui}

$(x+100$

$\mathrm{p}=0.006, \mathrm{R}^{2}=0.26$

Thi: $\mathbf{R}=\mathbf{- 0 . 2 5}$

Sesqui: $R=0.33$ Terp_tot: $R=-0.22$ Terp_Tot $\mathrm{p}<0.0001, \mathrm{R}^{2}=0.81$

Thi: $R=-0.78$

Thi

$* *$

$\mathrm{p}=0.020, \mathrm{R}^{2}=0.16$

FMC: $\mathrm{R}=\mathbf{- 0 . 4 0}$

$\mathrm{p}<0.0001$

$\mathrm{R}^{2}=0.80$

Thi: $\mathbf{R}=\mathbf{- 0 . 7 9}$

Terp_tot: $\mathbf{R}=\mathbf{- 0 . 2 2}$

FMC: $\mathrm{R}=\mathbf{- 0 . 4 2}$ FMC

$* * *$ 
Thi: $\mathbf{R}=\mathbf{0 . 3 0}$

FMC: $\mathbf{R}=\mathbf{0 . 2 1}$

FMC

Terp_tot: $\mathrm{R}=0.14$ 
1 Table 4. Results of the partial least squares regression analyses (PLS) highlighting the significant fuel characteristics impacting litter flammability variables. A second PLS was run after the bootstrap procedure to obtain the correlation coefficients of the significant variables. Analyses were 3 separately run taking into account either the terpene content of the different subgroups or the total terpene content (in bold: significant fuel characteristics, p: p value, $\mathrm{R}^{2}$ : adjusted coefficient of determination, $\mathrm{R}$ : correlation coefficient; TTI: time-to-ignition, $\mathrm{T}_{\mathrm{MAX}}$ : maximal temperature,

5 FD: flaming duration, $\mathrm{T}_{\mathrm{TTI}}$ : ignition temperature, FMC: fuel moisture content, Thi: leaf thickness, Mono: monoterpene content, Sesqui:

6 sesquiterpene content, Di: diterpene content, Terp_tot : total terpene content; bootstrap p-value: $* * *: p>0.01, * *: p=0.01, *: p=0.05$, boot

7 size $=1000$ ). Litter IF was not taken into account in the analysis as this variable scored $100 \%$ for all species.

\begin{tabular}{|c|c|c|c|c|c|c|c|c|}
\hline \multirow{2}{*}{$\begin{array}{l}\text { Flammability } \\
\text { variable }\end{array}$} & \multicolumn{2}{|c|}{ Analyses with content of terpene } & \multicolumn{2}{|c|}{ subgroups } & \multicolumn{4}{|c|}{ Analyses with total terpene content } \\
\hline & Results of PLS1 & After boostrap & P-value & Results of PLS2 & Results of PLS1 & After boostrap & P-value & Results of PLS2 \\
\hline \multirow[t]{6}{*}{ TTI } & $\mathrm{p}=0.004, \mathrm{R}^{2}=0.33$ & & & $\mathrm{p}=0.013, \mathrm{R}^{2}=0.20$ & $\mathrm{p}=0.005, \mathrm{R}^{2}=0.25$ & & & $\mathrm{p}=0.013, \mathrm{R}^{2}=0.20$ \\
\hline & Thi: $\mathbf{R}=\mathbf{0 . 3 6}$ & Thi & $*$ & Thi: $\mathbf{R}=\mathbf{0 . 4 5}$ & Thi: $\mathbf{R}=\mathbf{0 . 5 2}$ & Thi & $* * *$ & Thi: $\mathbf{R}=\mathbf{0 . 4 5}$ \\
\hline & FMC: $\mathrm{R}=-0.17$ & & & & FMC: $\mathrm{R}=-0.08$ & & & \\
\hline & Mono: $\mathrm{R}=0.20$ & & & & Terp_tot: $\mathrm{R}=0.10$ & & & \\
\hline & Sesqui: $\mathbf{R}=\mathbf{- 0 . 2 6}$ & & & & & & & \\
\hline & Di: $R=-0.06$ & & & & & & & \\
\hline \multirow[t]{2}{*}{ Tmax } & $\mathrm{p}=0.003, \mathrm{R}^{2}=0.27$ & NS & & & $\mathrm{p}=0.001, \mathrm{R}^{2}=0.31$ & & & $\mathrm{p}=0.003, \mathrm{R}^{2}=0.27$ \\
\hline & Thi: $\mathrm{R}=-0.02$ & & & & Thi: $R=-0.04$ & & & Terp_Tot:R=0.52 \\
\hline
\end{tabular}


FMC: $\mathrm{R}=0.16$

Mono: $\mathbf{R}=\mathbf{0 . 2 4}$

Sesqui: $\mathrm{R}=-0.002$

Di: $\mathbf{R}=\mathbf{- 0 . 2 5}$

FD

$\mathrm{p}=0.0002, \mathrm{R}^{2}=0.57$

Thi: $\mathbf{R}=\mathbf{-} 0.61$

FMC: $\mathrm{R}=0.18$

Mono: $\mathrm{R}=\mathbf{- 0 . 4 3}$

Sesqui: $\mathbf{R}=\mathbf{-} \mathbf{0 . 4 2}$

Di: $\mathbf{R}=\mathbf{0 . 3 4}$

$\mathrm{T}_{\mathrm{TTI}}$ $\mathrm{p}=0.010, \mathrm{R}^{2}=0.34$

Thi: $\mathbf{R}=\mathbf{0 . 5 8}$

FMC: $\mathrm{R}=-0.04$

Mono: $\mathbf{R}=\mathbf{0 . 3 9}$

Sesqui: $\mathbf{R}=\mathbf{0 . 3 3}$

Di: $R=-0.04$

\section{FMC: $\mathbf{R}=\mathbf{0 . 2 4}$}

Terp_tot:R= 0.45 Terp_tot

$* * *$

Thi

$* * *$

$\mathrm{p}<0.0001, \mathrm{R}^{2}=0.56 \mathrm{p}=0.002, \mathrm{R}^{2}=0.36$

$\mathrm{p}=0.003, \mathrm{R}^{2}=0.35$

Mono

Sesqui

Di

Thi: $\mathrm{R}=-\mathbf{0 . 5 6}$ Thi: $\mathrm{R}=\mathbf{- 0 . 5 2}$ Thi

Mono: $\mathrm{R}=\mathbf{- 0 . 5 2}$ FMC: $\mathrm{R}=\mathbf{0 . 4 4} \quad$ FMC

$* * *$

FMC: $\mathbf{R}=\mathbf{0 . 4 1}$

$* *$

***

Sesqui: $\mathbf{R}=\mathbf{- 0 . 4 2}$ Terp_tot: $\mathrm{R}=-0.11$

$\mathrm{Di}: \mathbf{R}=\mathbf{0 . 4 9}$

$\mathrm{p}=0.014, \mathrm{R}^{2}=0.20 \quad \mathrm{p}=0.032, \mathrm{R}^{2}=0.28$

$\mathrm{p}=0.014, \mathrm{R}^{2}=0.20$

Thi

$* *$

Thi: $\mathbf{R =} 0.44$

Thi: $\mathbf{R}=\mathbf{0 . 5 3}$

Thi

$* * *$

Thi: $\mathbf{R}=0.44$
FMC: $\mathrm{R}=-0.15$

Terp_tot: $\mathbf{R}=\mathbf{0 . 2 9}$ 